\title{
的 \\ Towards the establishment and standardization of a veterinary antimicrobial resistance surveillance and monitoring programme in South Africa
}

\author{
H. NEL ${ }^{1}, M$. VAN VUUREN ${ }^{1}$ and G.E. SWAN ${ }^{2}$
}

\begin{abstract}
NEL, H., VAN VUUREN, M. \& SWAN, G.E. 2004. Towards the establishment and standardization of a veterinary antimicrobial resistance surveillance and monitoring programme in South Africa. Onderstepoort Journal of Veterinary Research, 71:239-246

The objective of this study was to establish a repeatable, standardized laboratory procedure for monitoring the development of antimicrobial resistance in bacteria isolated from animals and food of animal origin in South Africa, with reagents prepared in-house. The emergence of resistance and the spread of resistant bacteria can be limited by implementing a veterinary antimicrobial drug policy, in which inter alia systematic monitoring and prudent use play essential roles.

The bacteria included in this study represented three different categories, namely zoonotic bacteria (Salmonella), indicator bacteria (Escherichia coli, Enterococcus faecalis and Enterococcus faecium) and veterinary pathogens (Mannheimia haemolytica). Thirty isolates of each species were collected with the aim of standardizing the laboratory methodology for a future national veterinary surveillance and monitoring programme. Susceptibility to ten selected antimicrobial drugs was determined by means of minimum inhibitory concentrations (MICs) using the microdilution method. The method according to the National Committee for Clinical Laboratory Standards was used as the standard.

Multi-well plates containing varying dilutions of antimicrobial drugs and prepared in-house for MIC determinations, yielded repeatable results. Storage of plates for 2 months at $-70^{\circ} \mathrm{C}$ did not influence results meaningfully. Within this limited sample of bacteria, MIC results did not indicate meaningful resistance against any of the ten selected antimicrobial drugs.

The findings of the study will be used to establish a national veterinary antimicrobial resistance surveillance and monitoring programme in South Africa. To allow for international comparison of data, harmonisation of the surveillance and monitoring programme in accordance with global trends is encouraged. Ideally it should be combined with a programme monitoring the quantities of antimicrobial drugs used. The aim is to contribute to slowing down the emergence of resistance and the problems associated with this phenomenon by means of the rational use of antimicrobial drugs.
\end{abstract}

Keywords: Antimicrobial resistance, harmonisation, minimum inhibitory concentration, monitoring

\section{INTRODUCTION}

Antimicrobial drugs have been used in animals since shortly after their introduction to human medicine.

\footnotetext{
Department of Veterinary Tropical Diseases, Faculty of Veterinary Science, Private Bag X04 Onderstepoort, 0110 South Africa

2 Department of Paraclinical Sciences, Faculty of Veterinary Science, Private Bag X04, Onderstepoort, 0110 South Africa

Accepted for publication 7 April 2004-Editor
}

They have been of great benefit to animals in terms of alleviation of suffering and to humans in helping to meet the growing demand for animal protein and in controlling the agents of potentially serious zoonoses (Martel, Chaslus-Dancla, Coudert, Poumart \& Lafont 1995). However, through the increasing use of antimicrobial drugs in humans, animals, fish and crops, an antimicrobial resistance problem has been created that is rapidly moving internationally to the forefront of public health concerns (Anon. 1999) with numerous governmental and non-gov- 
ernmental organizations being involved (Caprioli, Busani, Martel \& Helmuth 2000).

The role and impact of the use of antimicrobial drugs in animals on the development of bacterial resistance against these drugs have not clearly been delineated. While there is general concern about the emergence of antimicrobial resistance, the important aspect for the animal industries is the concern about the human health aspects of antimicrobial resistance that result from the use of antimicrobial drugs in animals, particularly their use for growth enhancement and disease prophylaxis and the relative volumes of antimicrobial drugs used in animals vs those used in humans. Two critical issues that linked the use of antimicrobial drugs in animals and public health concerns were the use of antimicrobial drugs as digestive enhancing drugs (growth promoters) and work done in Denmark that demonstrated the emergence of vancomycin-resistant enterococci and its association with the use of a glycopeptide antibiotic, avoparcin in animals (Woodford 1998). More recently, the potential impact of resistant Campylobacter infections in humans owing to fluoroquinolone use in chickens also contributed to concerns relating to the use of antimicrobial drugs in food producing animals. It is therefore necessary that the risk of development of resistance be considered by the animal industries and that surveillance for resistance and guidelines for the prudent use of antimicrobial drugs be established.

Antimicrobial drugs are considered essential for controlling bacterial infection and are among the most commonly used drugs in veterinary medicine. To safeguard the efficacy of their use in veterinary medicine and to minimize possible public health risks, the emergence of resistance and the spread of resistant bacteria must be limited by implementing a veterinary antibiotic policy in which, inter alia, systematic monitoring for the development of resistance and prudent use of such drugs play essential roles (Martel et al. 1995; Anon. 1999).

The monitoring of antimicrobial resistance in bacteria from animal sources in South Africa is in its infancy. However, the veterinary profession in this country recognizes it as an emerging problem and seeks to address the problem by developing and implementing a national antimicrobial strategy for the use of antimicrobials in animals which inter alia will include the need for a standardized monitoring programme. The ultimate goal for a national antimicrobial strategy is to prolong the efficacy of existing and new antimicrobial agents that are needed to control both human and animal infectious diseases and to minimize infections with zoonotic pathogens in humans (Tollefson, Angulo, Fedorka-Cray 1998).

The objectives of the study were to establish a repeatable, standardized laboratory procedure that can be used for monitoring the development of antimicrobial resistance in bacteria isolated from animals and food of animal origin in South Africa, and to make recommendations for the practical implementation of a monitoring programme that can provide information on a national scale.

\section{MATERIALS AND METHODS}

\section{Specimens}

Specimens for the isolation of bacteria and stored isolates of bacteria were obtained from the bacteriology laboratory and poultry reference laboratory, Department of Veterinary Tropical Diseases, Faculty of Veterinary Science, University of Pretoria, the Onderstepoort Veterinary Institute and Du Buisson, Bruinette \& Kramer, Medical Pathologists, Pretoria. In addition, lung specimens were obtained from various cattle feedlots in South Africa. Thirty isolates of each species of bacterium identified for possible inclusion in a future surveillance programme were collected and stored for testing. They included representatives of zoonotic pathogens (Salmonella), indicator bacteria of animal origin (Escherichia coli, Enterococcus faecium and Enterococcus faecalis) and a veterinary pathogen (Mannheimia haemolyti$c a)$. Some strains of $E$. faecalis of human origin were also included to make up the selected number of thirty isolates per bacterial species.

The specimens were randomly collected but formal randomization was not carried out. When isolates of bacteria were received from participating laboratories, they were examined for purity and viability, and their identification confirmed by performing relevant tests. Pure strains of overnight growth of each organism were inoculated into Brain Heart Infusion broth (CA Milsch), transferred to sterile vials and stored at $-70^{\circ} \mathrm{C}$.

\section{Microdilution susceptibility test}

Direct phenotypic susceptibility testing in which the lowest concentration of an antimicrobial drug that can effectively inhibit bacterial cell division is determined, was used. Sterile, plastic, microdilution plates with round wells (Sterilab), each containing $0.05 \mathrm{~m} \ell$ of cation-adjusted Mueller-Hinton broth (CA Milsch), was used. Enhanced growth and greater consisten- 
cy was obtained when testing Mannheimia haemolytica by supplementing the Mueller-Hinton broth with $0.1 \mathrm{~m} \ell$ inactivated bovine serum prior to inoculation. The inoculum was prepared by emulsifying bacterial colonies in a tube containing $5 \mathrm{~m} \ell$ of MuellerHinton broth and standardizing the concentrations spectrophotometrically. Each well of a freshly prepared or stored plate was inoculated with $0.05 \mathrm{~m} \ell$ of inoculum within $15 \mathrm{~min}$ after it was standardized. Plates were incubated at $35^{\circ} \mathrm{C}$ for $16-20 \mathrm{~h}$ in an aerobic incubator in stacks of not more than four plates to ensure that even incubation temperatures were kept.

\section{Antimicrobial drugs}

The plates containing the varying dilutions of the antimicrobial drugs for testing were prepared inhouse. The document entitled Performance Standards for Antimicrobial Disk and Dilution Susceptibil-

TABLE 1 Minimum Inhibitory Concentrations (MIC) recorded for antimicrobial drugs tested against the different isolates

\begin{tabular}{|c|c|c|}
\hline Antimicrobial & Organism & MIC results in $\mu \mathrm{g} / \mathrm{m} \ell$ \\
\hline Enrofloxacin & $\begin{array}{l}\text { Salmonella } \\
\text { E. coli } \\
\text { M. haemolytica } \\
\text { E. faecalis, E. faecium }\end{array}$ & $\begin{array}{l}<0.03-2 \\
<0.03->4 \\
<0.03-0.5 \\
0.125->4\end{array}$ \\
\hline Oxytetracycline & $\begin{array}{l}\text { Salmonella } \\
\text { E. coli } \\
\text { M. haemolytica } \\
\text { E. faecalis, E. faecium }\end{array}$ & $\begin{array}{l}2->64 \\
4->64 \\
<0.5->64 \\
<0.5->64\end{array}$ \\
\hline Gentamicin & $\begin{array}{l}\text { Salmonella } \\
\text { E. coli } \\
\text { M. haemolytica } \\
\text { E. faecalis, E. faecium }\end{array}$ & $\begin{array}{l}0.5->32 \\
0.5-8 \\
0.5-8 \\
1-32\end{array}$ \\
\hline Florfenicol & $\begin{array}{l}\text { Salmonella } \\
\text { E. coli } \\
\text { M. haemolytica } \\
\text { E. faecalis, E. faecium }\end{array}$ & $\begin{array}{l}4->16 \\
4->16 \\
0.5-4 \\
1-4\end{array}$ \\
\hline Amoxycillin & $\begin{array}{l}\text { Salmonella } \\
\text { E. coli } \\
\text { M. haemolytica } \\
\text { E. faecalis, E. faecium }\end{array}$ & $\begin{array}{l}<0.5->32 \\
<0.5->32 \\
<0.5-16 \\
<0.5-4\end{array}$ \\
\hline Neomycin & $\begin{array}{l}\text { Salmonella } \\
\text { E. coli } \\
\text { M. haemolytica } \\
\text { E. faecalis, E. faecium }\end{array}$ & $\begin{array}{l}<1-32 \\
<1-128 \\
2-32 \\
8->128\end{array}$ \\
\hline Tilmicosin & $\begin{array}{l}\text { Salmonella } \\
\text { E. coli } \\
\text { M. haemolytica } \\
\text { E. faecalis, E. faecium }\end{array}$ & $\begin{array}{l}64->64 \\
64->64 \\
<0.5-32 \\
<0.5->64\end{array}$ \\
\hline $\begin{array}{l}\text { Trimethoprim/ } \\
\text { Sulfamethoxazole }\end{array}$ & $\begin{array}{l}\text { Salmonella } \\
\text { E. coli } \\
\text { M. haemolytica } \\
\text { E. faecalis, E. faecium }\end{array}$ & $\begin{array}{l}<0.125->16 \\
<0.125->16 \\
<0.125 \\
<0.125-1\end{array}$ \\
\hline Sulfadimethoxine & $\begin{array}{l}\text { Salmonella } \\
\text { E. coli } \\
\text { M. haemolytica } \\
\text { E. faecalis, E. faecium }\end{array}$ & $\begin{array}{l}<0.125->512 \\
32->512 \\
<4-256 \\
<4->512\end{array}$ \\
\hline Cephalexin & $\begin{array}{l}\text { Salmonella } \\
\text { E. coli } \\
\text { M. haemolytica } \\
\text { E. faecalis, E. faecium }\end{array}$ & $\begin{array}{l}4->8 \\
4->8 \\
<0.125-4 \\
0.5->8\end{array}$ \\
\hline
\end{tabular}


ity Tests for Bacteria Isolated from Animals was used as the guidance document (National Committee for Clinical Laboratory Standards 1999).

Briefly, antimicrobial stock solutions were prepared by weighing the powders and dissolving them to yield the required concentrations based on the potency of the respective antimicrobial drugs. Some of the drugs had to be dissolved in solvents other than water. In those cases only enough solvent was used to solubilize the antimicrobial powder to give a translucent solution. It was diluted further to the final stock concentration with water or the appropriate diluent. Aliquots of $1 \mathrm{~m} \ell$ of the stock solution were dispensed into sterile $2 \mathrm{~m} \ell$ Eppendorf tubes, sealed and stored at $-70^{\circ} \mathrm{C}$. Vials were removed when needed and used the same day. Any unused drugs were discarded at the end of the day.

Two-fold dilutions were used to dilute the antimicrobial drugs and their concentration ranges were determined by published breakpoints for the different antimicrobial drugs. The concentration ranges of the different doubling dilutions in $\mu \mathrm{g} / \mathrm{m} \ell$ were as follows: enrofloxacin (0.03-4), oxytetracycline (0.5-64), gentamicin (0.25-32), florfenicol (0.125-16), amoxycillin (0.5-32), neomycin (1-128), tilmicosin (0.5-64), trimethoprim/sulfamethoxazole (0.125/304-16/2.4), sulfadimethoxine (4-512) and cephalexin (0.125-8). For each antimicrobial concentration in the dilution range, aliquots of $0.05 \mathrm{~m} \ell$ were dispensed to the corresponding wells in each plate.

\section{Quality control}

The following reference strains of bacteria obtained from the American Type Culture Collection were used: Escherichia coli ATCC 25922, Pseudomonas aeruginosa ATCC 27853, Enterococcus faecalis
ATCC 29212, and Staphylococcus aureus ATCC 29213. The antimicrobial susceptibility of reference organisms was tested on each occasion that a new batch of microdilution plates was prepared. When the minimum inhibitory concentrations (MICs) of the reference strains did not fall between the ranges according to the requirements of the National Committee for Clinical Laboratory Standards (NCCLS), the plates were discarded. The results of these tests were compared with the expected values given by the NCCLS in Table 4 of Document M31-A, for accuracy. Results were recorded on a quality-control record sheet. Other control procedures included growth control, purity control and inoculum control (Sahm \& Washington 1991; NCCLS 1999).

\section{Repeatability}

Susceptibility tests were done twice for each individual bacterial organism to determine the inter-plate variation of microdilution plates. In addition, prepared plates were stored frozen at $-70^{\circ} \mathrm{C}$ until required for use. As the plates were filled, they were stacked in groups of five plates and covered with an adhesive seal. In this way, each tray fitted on top of the other tightly enough to provide a cover that minimizes evaporation and contamination. Each stack was then sealed in a plastic bag. These were thawed and tested 2 months after freezing to determine the influence of storage temperature on the repeatability of the test. Prior to inoculation, the plates were thawed at room temperature for approximately $1 \mathrm{~h}$ before use.

\section{RESULTS}

The MIC range of each organism tested against each antimicrobial drug is indicated in Table 1.

TABLE 2 Repeatability results of duplicate testing of selected antimicrobial drugs against four bacterial species

\begin{tabular}{|l|l|l|l|l|}
\hline \multirow{2}{*}{ Antimicrobial drug } & \multicolumn{4}{l|}{ Percentage of repeat analyses within one dilution } \\
\cline { 2 - 5 } & Salmonella & E. coli & $\begin{array}{l}\text { Mannheimia } \\
\text { haemolytica }\end{array}$ & $\begin{array}{l}\text { E. faecalis, } \\
\text { E. faecium }\end{array}$ \\
\hline Enrofloxacin & & 90.0 & 100.0 \\
Oxytetracycline & 93.33 & 100.0 & 90.0 & 86.67 \\
Gentamicin & 93.33 & 93.33 & 100.0 & 96.67 \\
Florfenicol & 96.67 & 93.33 & 100.0 & 100.0 \\
Amoxycillin & 96.67 & 100.0 & 96.67 & 100.0 \\
Neomycin & 90.0 & 90.0 & 100.0 & 93.33 \\
Tilmicosin & 100.0 & 96.67 & 100.0 & 93.33 \\
Trimethoprim/Sulfa & 100.0 & 90.0 & 100.0 & 100.0 \\
Sulfadimethoxine & 96.67 & 90.0 & 96.67 & 96.67 \\
Cephalexin & 100.0 & 100.0 & 100.0 & 100.0 \\
\hline
\end{tabular}


H. NEL, M. VAN VUUREN \& G.E. SWAN

\section{Repeatability of test}

Table 2 shows the repeatability in percentage of the duplicate test results, allowing a difference in MIC values corresponding to one $\log _{2}$ dilution step. All the antimicrobial drugs, except for oxytetracycline, when tested against $E$. faecalis and $E$. faecium gave a repeatability percentage of $90 \%$ and higher. An overall agreement of $96.5 \%$ was obtained between the 120 specimens and panel of antimicrobial drugs.

\section{Effect of storage}

The results given in Table 3 represent the data collected after testing the reference strains on plates that were stored at $-70^{\circ} \mathrm{C}$ for 2 months.

\section{DISCUSSION}

The microdilution minimal inhibitory concentration antimicrobial susceptibility test was chosen as the test of choice for future antimicrobial resistance surveillance and monitoring because it overcomes several limitations of the disk diffusion test. It is a quantitative determination of the degree of susceptibility, not dependent on subjective interpretation, measurement of zones of growth inhibition or extrapolation of MIC values from zone sizes. The precise amount of antimicrobial drug required to inhibit bacterial growth can be determined (Fales, Morehouse, Mittal, Bean-Knudsen, Nelson, Kintner, Turk, Turk,
Brown \& Shaw 1989). The MIC is generally a reproducible quantitative characteristic of the bacterial isolate that can be measured readily (Prescott \& Baggot 1985). In addition, quantitative susceptibility testing using the microdilution method is preferred when testing bacteria of frequently unpredictable susceptibility, such as Salmonella and E. coli. It is also the method of choice when testing bacteria that have developed multiple drug resistance (Baggot 1998).

The guidelines of the NCCLS were used as the reference method for preparing the varying dilutions of antimicrobial drugs and determining the minimum inhibitory concentrations. It is the quantitative method used by most countries for the determination of susceptibility of bacteria. The NCCLS has also developed protocols for susceptibility testing of bacteria of animal origin and the determination of the interpretive criteria. The World Organisation for Animal Health (OIE) (Anon. 1999) has endorsed the use of NCCLS standards and guidelines (Franklin, Acar, Anthony, Gupta, Nicholls, Tamura, Thompson, Threlfall, Vose, Van Vuuren, White, Wegener \& Costarrica 2001). Using the microdilution method standardized by the NCCLS will contribute to harmonisation of laboratory methodologies and allow more meaningful comparisons of data.

Values obtained for each of the ten antimicrobial agents used against each isolate were generally

TABLE 3 Minimum inhibitory concentrations of reference strains tested after plates were stored frozen for 2 months

\begin{tabular}{|c|c|c|c|c|c|c|c|c|}
\hline \multirow{2}{*}{ Drugs } & \multicolumn{2}{|c|}{$\begin{array}{l}\text { Staphylococcus aureus } \\
\text { ATCC } 29213\end{array}$} & \multicolumn{2}{|c|}{$\begin{array}{l}\text { Enterococcus faecalis } \\
\text { ATCC } 29212\end{array}$} & \multicolumn{2}{|c|}{$\begin{array}{l}\text { Escherichia coli } \\
\text { ATCC } 25922\end{array}$} & \multicolumn{2}{|c|}{$\begin{array}{l}\text { Pseudomonas aeruginosa } \\
\text { ATCC } 27853\end{array}$} \\
\hline & $\begin{array}{l}\text { Control } \\
\text { Limits }^{a}\end{array}$ & Results $^{b}$ & $\begin{array}{l}\text { Control } \\
\text { Limits }\end{array}$ & Results & $\begin{array}{l}\text { Control } \\
\text { Limits }\end{array}$ & Results & $\begin{array}{l}\text { Control } \\
\text { Limits }\end{array}$ & Results \\
\hline 1 & $0.03-0.12$ & 0.06 & $0.12-1$ & 0.25 & $0.008-0.03$ & $<0.03$ & $1-4$ & 4 \\
\hline 2 & $0.25-1$ & 0.5 & $8-32$ & 8 & $0.05-2$ & 2 & $8-32$ & 8 \\
\hline 3 & $0.12-1$ & 0.5 & $4-16$ & 16 & $0.25-1$ & 1 & $0.5-2$ & 2 \\
\hline 4 & $2-8$ & 2 & $2-8$ & 2 & $2-8$ & 8 & $>16$ & $>16$ \\
\hline 5 & $0.25-1$ & 0.5 & $0.5-2$ & 0.5 & $2-8$ & 4 & - & - \\
\hline 6 & $1-4$ & 2 & $16-64$ & 16 & $1-4$ & 2 & - & - \\
\hline 7 & $1-4$ & 1 & $\geq 32$ & & $\geq 64$ & $>64$ & $>16$ & $>16$ \\
\hline 8 & $\leq 0.5 / 9.5$ & 0.5 & $\leq 0.5 / 0.9$ & $<0.125$ & $\leq 0.5 / 9.5$ & $<0.125$ & $\begin{array}{l}8 / 152- \\
32 / 608\end{array}$ & 32 \\
\hline 9 & $32-128$ & 32 & $32-128$ & 32 & $8-32$ & 8 & - & - \\
\hline 10 & $0.12-0.5$ & 0.5 & - & - & $4-16$ & 4 & - & - \\
\hline
\end{tabular}

a Accepted quality control ranges of MICs $(\mu \mathrm{g} / \mathrm{m} \ell)$ for reference strains, derived from NCCLS, Table 4, Document M31-A, vol. 19, no. 11, June 1999

b Results $(\mu \mathrm{g} / \mathrm{m} \ell)$ after storage for 2 months at $-70^{\circ} \mathrm{C}$

(1) enrofloxacin; (2) oxytetracycline; (3) gentamicin; (4) florfenicol; (5) amoxycillin; (6) neomycin; (7) tilmicosin; (8) trimethoprim/sulfamethoxazole; (9) sulfadimethoxine; (10) cephalexin 
similar to those reported in related studies (Post, Cole \& Raleigh 1991; Burrows, Morton \& Fales 1993; Watts, Salmon, Yancey, Nersession \& Kounev 1993; Hirsh \& Jang 1994; Bengtsson, Franklin, Greko, Karlsson \& Wallen 2000). However, different MIC values were obtained for neomycin against $E$. coli and Salmonella. Some of the results fell within comparable ranges, but a high percentage of MICs were also found to be $<1 \mu \mathrm{g} / \mathrm{m} \ell$. A particularly large deviation was found with sulfadimethoxine against $M$. haemolytica. The highest recorded MIC value in this study was $>256 \mu \mathrm{g} / \mathrm{m} \ell$ whilst the greatest distribution of MICs were obtained at a dilution of $<64$ $\mu \mathrm{g} / \mathrm{m} \ell$ and $128 \mu \mathrm{g} / \mathrm{m} \ell$. This could be owing to the use of samples from diagnostic submissions in this study, whereas comparative studies made use of specimens taken from healthy animals.

The results of microdilution susceptibility testing are considered to be satisfactory if the results of individual tests vary no more than plus or minus one serial dilution. The results of the two replicate tests in this project revealed agreement within one dilution for most organisms tested. To determine whether repeatability is adequate, it is considered necessary to calculate the coefficients of variation (SD of replicates divided by mean of replicates) (Jacobson 1998). However, to do these calculations continuous data are required but not discrete data as was the case in this study. This is owing to the fact that the results are also considered to be concordant when the independent tests vary by one serial dilution. Using the standardized method of the NCCLS, with all the quality control measures, the results showed $90 \%$ comparability, except for oxytetracycline that showed $86.67 \%$ comparability. The data thus indicated a high degree of correlation between the two sets of test results.

Stability was shown for plates prepared in-house and frozen for a period of 2 months. Therefore, microtitre plates containing the antimicrobial drugs in suspension can be safely stored at $-70^{\circ} \mathrm{C}$ for at least 2 months following preparation. The results point to the fact that custom-made microdilution plates are as good as commercially produced plates provided that universally accepted quality control strains are always included. In this regard, the ATCC control strains are satisfactory as far as susceptible strains are concerned. However, national reference laboratories should also strive to measure results against resistant strains.

Most clinical specimens from which the bacterial species used in this study were isolated were diagnostic submissions and the results must therefore be interpreted with caution. Bacteria from these types of submissions tend to be species from severe and/or recurrent clinical cases and some may possess some degree of antimicrobial resistance. Thus, the prevalence of resistant strains may be overestimated and may not reflect the resistance situation in the animal population as a whole (Bengtsson et al. 2000). The number of bacterial species used in this study was relatively small and cannot be considered as representative of resistance patterns for the bacteria tested. Based on knowledge of antimicrobial drug use in production animals in South Africa, a future surveillance programme should ideally include specimens from adult cattle and calves, slaughter pigs, broiler chickens and layer hens. In addition, it is recommended that active surveillance as opposed to passive surveillance be conducted. The former represents a sampling scheme where the nature and number of specimens are defined and collection takes place at regular intervals to assure consistency.

The structure of a veterinary antimicrobial surveillance and monitoring programme will of necessity have a different emphasis when compared with similar programmes for humans. The amount of data regularly generated in human hospitals is uncommon in the veterinary field, probably because a variety of animal species must be included. Veterinary antimicrobial surveillance and monitoring programmes should aim at detecting the level of resistance in bacteria isolated both from animals and animal-derived foods, at evaluating the risks of the use of antimicrobial drugs in animals and at quantifying the impact of these findings on human health (Moreno, Dominguez, Teshager, Herrero \& Porrero 2000).

Specimen collection can include diagnostic submissions that are readily available, but the emphasis should be on field specimens taken from healthy animals, food of animal origin and abattoirs. All specimens collected should preferably be from food producing animals, and sampling done randomly to avoid bias. Specimens can be collected weekly, monthly, or otherwise as required. The OIE guidance document (Franklin et al. 2001) is not prescriptive about the exact number of specimens to be collected. Thus, it is recommended that an optimal number of specimens as determined by available resources be collected and included to give a true reflection and valid statistical results.

The OIE has recommended certain bacterial species that could be included in surveillance programmes. These are grouped under the following 
three major categories of organisms (Franklin et al. 2001):

- Veterinary pathogens: Pasteurella spp., Haemophilus somnus, Actinobacillus pleuropneumoniae, E. coli, Salmonella serotypes, Staphylococcus aureus, Streptococcus spp. from udder specimens, Streptococcus suis, Brachyspira spp. and Aeromonas and Vibrio spp. from fish specimens.

- Zoonotic bacteria: Salmonella Typhimurium, Salmonella Enteritidis, Campylobacter jejuni, Campylobacter coli and an enterohaemorrhagic $E$. coli such as 0157.

- Commensal/indicator bacteria: E. coli and enterococci especially, E. faecium. The latter bacteria are known to be indicators of antimicrobial resistance and should be obtained from healthy animals.

For a national surveillance and monitoring programme in South Africa, it is recommended that the bacterial species tested in this study are included. They represent the three major categories of organisms and, in the developmental stages of the programme, will not provide a formidable challenge in terms of isolation and identification. Additional organisms and types of specimens can be included when available resources and capacity make it possible. For example, it may be worthy of consideration to restrict Salmonella monitoring to bovine and porcine specimens and include Campylobacter spp. isolations from poultry specimens.

The antimicrobial drugs included in this study are similarly recommended for the initial phase of the programme. They represent most of the important antimicrobial classes used in animals and humans. The selection of two aminoglycosides within the panel of antimicrobials was based on the gastrointestinal specific action of neomycin compared to systemic antibacterial indications of gentamicin (Prescott 2000). The difference in the aminoglycoside-modifying enzymes in $\mathrm{R}$ plasmid-bearing bacteria between neomycin and gentamicin was also considered (Lambert \& O' Grady 1992). Explosive outbreaks of nosocomial infections caused by gentamicin-resistant bacteria of many species have been reported in human hospitals (Prescott 2000). Neomycin plasmid-mediated resistance is relatively common in enteric commensals and pathogens but less common among other opportunist pathogens. Other drugs can be considered for inclusion at later stages, for example antimicrobial drugs that are used in humans and not in animals (e.g. glycopeptides and streptogramins). It would be ideal to develop antimicrobial panels for each category of bacteria to be tested. Antimicrobial panels can also be designed specifically for Gram-negative and Gram-positive bacteria or for each bacterial species tested in the surveillance programme (Aarestrup, Bager, Jensen, Madsen, Meyling \& Wegener 1998; Moreno et al. 2000; Aarestrup 2000; Franklin et al. 2001).

Information on the consumption of antimicrobial drugs used in different animal species is also needed to assess the impact on the occurrence of resistance and to determine where and for which infections most antimicrobial drugs are used. A key use of surveillance data is to relate this to antimicrobial use so that where resistance emerges, appropriate feedback exists and measures can be taken by regulatory authorities to address use patterns that may be contributing to the emergence of resistance. Cautious, rational, quantitatively and qualitatively adjusted use of antimicrobial drugs in human and veterinary medicine will at least slow down the emergence of resistance and the problems associated with this phenomenon (Aarestrup 2000; Cohen \& Tartasky 1997).

At present, information on antimicrobial resistance in bacteria from animals is lacking in most countries. A structured surveillance and monitoring programme for antimicrobial resistance in South Africa will contribute to the detection of emerging resistance problems at the earliest possible stage.

\section{REFERENCES}

AARESTRUP, F.M., BAGER, F., JENSEN, N.E., MADSEN, M., MEYLING, A. \& WEGENER, H.C. 1998. Surveillance of antimicrobial resistance in bacteria isolated from food animals to antimicrobial growth promoters and related therapeutic agents in Denmark. APMIS, 106:606-622.

AARESTRUP, F.M. 2000. Occurrence, selection and spread of resistance to antimicrobial agents used for growth promotion for food animals in Denmark. APMIS 108(101 Suppl): 5S$48 \mathrm{~S}$.

ANONYMOUS 1999. OFFICE INTERNATIONAL DES EPIZOOTIES. The use of antibiotics in animals-ensuring the protection of public health. Summary and Recommendations from the European Scientific Conference, Paris, France, 2426 March 1999.

BENGTSSON, B., FRANKLIN, A., GREKO, C., KARLSSON, M., \& WALLEN, C. 2000. Swedish veterinary antimicrobial resistance monitoring. Uppsala, Sweden: Wikströms.

BAGGOT, J.D. 1998. Antimicrobial selection, administration and dosage. Journal of the South African Veterinary Association, 69:174-185.

BURROWS, G.E., MORTON, R.J. \& FALES, W.H. 1993. Microdilution antimicrobial susceptibilities of selected Gram-negative veterinary bacterial isolates. Journal of Veterinary Diagnostic Investigation, 5:541-547. 
CAPRIOLI, A., BUSANI, L., MARTEL, J.L. \& HELMUTH, R. 2000. Monitoring of antibiotic resistance in bacteria of animal origin: epidemiological and microbiological methodologies. International Journal of Antimicrobial Agents, 14:295-301.

COHEN, F., \& TARTASKY, D. 1997. Microbial resistance to drug therapy: A review. American Journal of Infection Control, 25: 51-64.

FALES, W.H., MOREHOUSE, L.G., MITTAL, K.R., BEANKNUDSEN, C., NELSON, S.L, KINTNER, L.D., TURK, J.R., TURK, M.A., BROWN, T.P. \& SHAW, D.P. 1989. Antimicrobial susceptibility and serotypes of Actinobacillus (Haemophilus) pleuropneumoniae recovered from Missouri swine. Journal of Veterinary Diagnostic Investigation, 1:1619.

FRANKLIN, A., ACAR, J., ANTHONY, F., GUPTA, R., NICHOLLS, T., TAMURA, Y., THOMPSON, S., THRELFALL, E.J., VOSE, D., VAN VUUREN, M., WHITE, D.G., WEGENER H.C. \& COSTARRICA, M.L. 2001. Antimicrobial resistance: harmonization of national antimicrobial resistance monitoring and surveillance programmes in animals and anima derived food. Revue Scientifique et Technique, 20:859-870.

HIRSH, D.C. \& JANG, S.S. 1994. Antimicrobial susceptibility of selected infectious bacterial agents obtained from dogs. Journal of the American Animal Hospital Association, 30:487494.

JACOBSON, R.H. 1998. Validation of serological assays for diagnosis of infectious diseases. Revue Scientifique et Technique, 17:469-486.

LAMBERT, H.P. \& O' GRADY, F.W. (Eds) 1992. Antibiotic and chemotherapy, $6^{\text {th }}$ ed., Edinburgh: Churchill Livingstone.

MARTEL, J.L., CHASLUS-DANCLA, E., COUDERT, M., POUMART, F. \& LAFONT, J.P. 1995. Survey of antimicrobial resistance in bacterial isolates from diseased cattle in France. Microbial Drug Resistance, 1:273-283.

MORENO, M.A., DOMINGUEZ, L., TESHAGER, T., HERRERO, I.A. \& PORRERO, M.C. 2000. Antibiotic resistance monitor- ing: the Spanish programme. International Journal of Antimicrobial Agents, 14: 285-290.

NATIONAL COMMITTEE FOR CLINICAL LABORATORY STANDARDS 1999. Performance standards for antimicrobial disk and dilution tests for bacteria isolated from animals: approved standard. Document M31-A, vol.19, no. 11, June 1999.

POST, K.W., COLE, N.A. \& RALEIGH, R.H. 1991. In vitro antimicrobial susceptibility of Pasteurella haemolytica and Pasteurella multocida recovered from cattle with bovine respiratory disease complex. Journal of Veterinary Diagnostic Investigation, 3:124-126.

PRESCOTT, M.A. \& BAGGOT, J.D. 1985. Antimicrobial susceptibility testing and antimicrobial drug dosage. Journal of the American Veterinary Medical Association, 187:363-368.

PRESCOTT, J.F. 2000. Aminoglycosides and aminocyclitols, in Antimicrobial therapy in veterinary medicine, edited by J.F. Prescott, J.D. Baggot \& R.D. Walker, $3^{\text {rd }}$ ed. Ames: lowa State University Press.

SAHM, D.F. \& WASHINGTON, J.A. 1991. Antibacterial susceptibility tests: Dilution methods, in Manual of clinical microbiology, edited by A. Balows, W.J. Hausler, K.L. Hermann, H.D. Isenberg \& H.J. Shadomy, $5^{\text {th }}$ ed. American Society for Microbiology, Washington, D.C.

TOLLEFSON, L., ANGULO, F.J. \& FEDORKA-CRAY, P.J. 1998. National surveillance for antibiotic resistance in zoonotic enteric pathogens. The Veterinary Clinics of North America: Food Animal Practice, 14:141-150.

WATTS, J.L., SALMON, S.A., YANCEY, R.J., NERSESSION, B. \& KOUNEV, Z.V. 1993. Minimum inhibitory concentrations of bacteria isolated from ducks with septicemia and airsacculitis. Journal of Veterinary Diagnostic Investigation, 5:625628.

WOODFORD, N. 1998. Glycopeptide-resistant enterococci: a decade of experience. Journal of Medical Microbiology, 47: 849-62. 